\title{
Eye care in ICU : What an ICU doctor need to know
}

\author{
Ashraf Sayeed and Md Ferdous Hossain
}

Eye care is an important aspect of managing the critically ill patient, as many of the mechanisms normally involved in protecting the eye from infection and injury are compromised ${ }^{1}$.Ocular surface disease is common in the intensive care population. Among them $20-42 \%$ of patients developing corneal epithelial defects. The ocular surface is normally protected by the ability to produce tears, to blink and to close the eyes with rest or sleep. All of these mechanisms can be disrupted in the intensive care population, increasing the risk of developing ocular surface disease. ${ }^{2}$ There is a strong correlation between lagophthalmos and the development of corneal erosion, which can then lead to keratitis or corneal ulceration..$^{3,4}$

On the other hand patients in intensive care units (ICU) are at increased risk of corneal abrasions and infectious keratitis due to impaired ocular defense mechanisms such as poor eyelid closure, inhibition of Bell's phenomenon, decreased blink reflex, reduced tear production, and increased exposure to pathogenic microorganisms, ${ }^{4-10}$ leading to corneal erosion, keratitis and some other eye problems. Ocular surface disease (OSD) can involve any of these structures and can present as:

1. Direct injury to the cornea - most often a superficial corneal abrasion (scratch)

2. Exposure keratopathy

3. Chemosis (conjunctival swelling)

\section{Microbial conjunctivitis and keratitis}

According to some author the development of OSD among ICU patients is common, affecting up to even $23-60 \%$ of patients ${ }^{4,5}$ Exposure keratopathy represents a dryness of the cornea due to incomplete lid closure allowing excessive tear evaporation and a consequent failure of the tears to spread adequately across the eye surface. ${ }^{7,11}$

There are some factors that may complicate the ocular problems. Risk factors include compromised venous return from the ocular structures (positive pressure ventilation, escalating positive end expiratory pressures or tight endotracheal tube taping), those states associated with generalized edema (such as fluid overload or hypoalbuminaemia), gravitational causes of increased hydrostatic pressure (prolonged recumbence or prone ventilation), or states that increase capillary leak (such as systemic inflammatory response syndromes). Chemosis can cause impaired eyelid closure, whilst incomplete eyelid closure can also predispose to chemosis. ${ }^{12}$ Respiratory secretions are thought to be the major source of ocular surface infection, with aerosols from tracheal suctioning and direct contact from suction catheters both being implicated. ${ }^{13}$ Rare eye conditions in ICU includes endogenous endophthalmitis. This is a very serious problem caused by spread of systemic infection in the blood stream and then to the inside of the eye. ${ }^{8,14}$

There are some other eye problems that can complicate ICU care. Severe or recurrent hypotension can cause blindness from ischaemic optic neuropathy. ${ }^{10,20}$ In those ventilated prone, increased intra-ocular pressures or intraorbital pressure with marked periocular swelling can decrease ocular perfusion pressures (worse with concurrent systemic hypotension), leading to ischaemic optic neuropathy, central retinal artery occlusion and permanent visual loss. ${ }^{9,15}$ Rarely, those nursed prone can develop bilateral acute glaucoma in which there is a sudden rise in intraocular pressure which can causes visual loss very quickly because of retinal or optic nerve ischemia. In this condition, the cornea becomes cloudy and grey and the pupil becomes fixed at a mid-dilated position and unresponsive to light. This needs immediate ophthalmic treatment. ${ }^{12,13,16}$

There are some pre existing factors that may complicate the ICU stay. These pre-existing risk factors include Bell's Palsy, Blepharitis ,Blepharoplasty, Coloboma, Ectropion, Entropion, Graves' disease, Myasthenia gravis, Parkinson's disease, Sjogren's syndrome, Symblepharon, Lagophthalmos, Floppy eyelid syndrome. ${ }^{17}$

Eye care of ICU patients is delivered by various ways. This is usually given in the form of drops or ointment. Sometimes several different drops are required. It should keep on mind that when giving several different drops, as instructed to give at the same time, as one drop may wash out another, thereby reducing its effectiveness. Ideally, there will be $5 \mathrm{~min}$ apart between each medication. It is also mandatory that always drops are used before ointment as the ointment is water repellent and prevents the drops from getting contact into the eye tissues. When putting in ointment in poor lid closure, after instilling ointment manually shut eyelids to ensure ointment is spread over whole eye surface. ${ }^{18}$

Use of swimming goggles and regular moistening of eyelids with gauze soaked in sterile water providing a moisture chamber, is more effective than using a combination of ocular lubricants and securing tape over the eyelids, in preventing corneal epithelial breakdown in sedated and semiconscious intensive care unit patients ${ }^{19}$. Where no other facility is available at least taping the eyes or lubricants eye ointment should be used to protect the eyes of ICU patients.

As ICU patients are more susceptible to develop dry eye, keratopathy, ocular infections and many other complications, they should be consulted by an ophthalmologist for early diagnosis and proper management ${ }^{9}$.

In ICU treatment is usually focused on the management of organ failures, and eye care becomes a side issue. But early diagnosis and effective treatment will prevent microbial 
keratitis and visual loss.

Our recommendations to critical care physicians are as follows

1. Protect the eyes in vulnerable patients, thus preventing ICU-related eye problems

2. Identify disease affecting the eyes in ICU patients, and specifically those might need ophthalmic referral

3. Meticulous delivery of treatment to the eye when it is prescribed. ${ }^{20}$

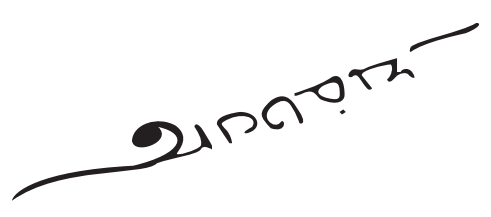

Professor Ashraf Sayeed

Professor and head, Department of Ophthalmology,

BIRDEM General Hospital.

E mail : ashrafsayeedbirdem86@yahoo.com

\section{Md. Thels}

Dr Md Ferdous Hossain

Registrar, Department of Ophthalmology,

BIRDEM General Hospital. Dhaka, Bangladesh.

E mail :ferdoushossain67@gmail.com

\section{References:}

1. Benjamin J Hearne, Elewys G Hearne, Hugh Montgomery,Susan L Lightman. Eye care in the intensive care unit. Journal of the Intensive Care Society 2018; 19(4): 345-350

2. Johnson K and Rolls K. Eye Care for Critically Ill Adults, Version 2. Chatswood, NSW: Agency for Clinical Innovation (ACI), Intensive Care Coordination and Monitoring Unit. 2014, pp.1-43

3. Fernando Ramírez, Sergio Ibarra, Joseph Varon, Rosa Tang. The Neglected Eye: Ophthalmological Issues in the Intensive Care Unit. Crit Care Shock. 2008; 11: 72-82.

4. Grixti A, Sadri M, Edgar J, Datta AV. Common ocular surface disorders in patients in intensive care units. Ocul Surf. 2012 Jan;10(1):26-42.
5. Joyce N. Eye care for the intensive care patient. A Systematic Review. No 21. The Joanna Briggs Institute for Evidence Based Nursing and Midwifery; Adelaide, Australia: 2002; 6: 1-6

6. Mela EK, Drimtzias EG, Christofidou MK, Filos KS, Anastassiou ED, Gartaganis SP. Ocular surface bacterial colonisation in sedated intensive care unit patients. Anaesth Intensive Care. 2010 Jan;38(1):190-3.

7. Kirwan JF, Potamitis T, El-Kasaby H, Hope-Ross MW, Sutton GA. Lesson of the week: microbial keratitis in intensive care. BMJ. 1997;314:433-434.

8. Hernandez EV, Mannis MJ. Superficial keratopathy in intensive care unit patients. Am J Ophthalmol. 1997;124(2):212-6.

9. Imanaka $\mathrm{H}$, Taenaka $\mathrm{N}$, Nakamura J, Aoyama K, Hosotani $\mathrm{H}$. Ocular surface disorders in the critically ill. Anesthesia and Analgesia.1997;85(2):343-347.

10. Mercieca F, Suresh P, Morton A, Tullo A. Ocular surface disease in intensive care unit patients. Eye (Lond). 1999 ;13 ( Pt 2):231-6.

11. Lenart SB, Garrity JA. Eye care for patients receiving neuromuscular blocking agents or propofol during mechanical ventilation. Am J Crit Care. 2000 ;9(3):188-91.

12. Suresh P, Mercieca F, Morton A, Tullo AB. Eye care for the critically ill. Intensive Care Med. 2000;26(2):162-166.

13. King S, Devi SP, Mindorff C, Patrick ML, Gold R, Ford-Jones EL Nosocomial Pseudomonas aeruginosa conjunctivitis in a pediatric hospital. Infection Control and Hospital Epidemiology. 1988;9(2):77-80.

14. Brito DV, de Brito CS, Resende DS, do Moreira JÓ, Abdallah VOS, Filho PPG. Nosocomial infections in a Brazilian neonatal intensive care unit: a 4-year surveillance study. Revista da Sociedade Brasileira de Medicina Tropical. 2010;43(6):633-637.

15. Hilton E, Uliss A, Samuels S, Adams AA, Lesser ML, Lowy FD Nosocomial bacterial eye infections in intensive-care units. Lancet. 1983 11;1(8337):1318-1320.

16. Bansal, S, Ansons, A, Vishwanath, M. Hypotension-induced blindness in haemodialysis patients. Clin Kidney J. August 2014; 7(4): 387-390

17. Benjamin Bird, Stephen Dingley, Stanislaw P. Stawicki and Thomas R. Wojda. Exposure keratopathy in the Intensive Care Unit: do not neglect the unseen. http//dx.doi.org/10.5772/intechopen.72791.

18. Hilton E, Adams AA, Uliss A, Lesser ML, Samuels S, Lowy FD. Nosocomial bacterial eye infections in intensive-care units. Lancet. 1983 Jun 11;1(8337):1318-20

19 Sivasankar S, Jasper S, Simon S, Jacob P, John G, Raju R. Eye care in ICU. Indian J Crit Care Med. 2006; 10 (1):11-4

20. Panchabhai TS, Bandyopadhyay D, Kapoor A. Acute ischemic optic neuropathy with extended prone position ventilation in a lung transplant recipient. Int J Crit Illn Inj Sci. 2016; 6: 45-47. 